FedUni ResearchOnline

http://researchonline.federation.edu.au

This is the author's accepted version of the following publication:

Khandelwal, M., Armaghani, D. (2015). Prediction of drillability of rocks with Strength Properties Using a Hybrid GA-ANN Technique.

Geotechnical and Geological Engineering Vol. p.1-16.

The version displayed here may differ from the final published version.

The final publication is available at:

http://doi.org/10.1007/s10706-015-9970-9

Copyright @ 2015, Springer-Verlag Berlin Heidelberg 


\title{
PREDICTION OF DRILLABILITY OF ROCKS WITH STRENGTH PROPERTIES USING A
} HYBRID GA-ANN TECHNIQUE

\section{Manoj Khandelwal ${ }^{1 *}$ and Danial Jahed Armaghani ${ }^{2}$}

${ }^{1 *}$ Faculty of Science and Technology, Federation University Australia, PO Box 663, Ballarat, Victoria 3353, Australia Phone: +61 353279821

Email: m.khandelwal@federation.edu.au.

\author{
${ }^{2}$ Department of Geotechnics and Transportation, Faculty of Civil Engineering, Universiti Teknologi
} Malaysia, 81310, UTM, Skudai, Johor, Malaysia. Email: danialarmaghani@gmail.com.

\section{Abstract}

The purpose of this paper is to provide a proper, practical and convenient drilling rate index (DRI) prediction model based on rock material properties. In order to obtain this purpose, 47 DRI tests were conducted in the laboratory. In addition, the relevant strength properties i.e. uniaxial compressive strength (UCS) and Brazilian tensile strength (BTS) were determined and selected as input parameters to predict DRI. Examined simple regression analysis showed that the relationships between the DRI and predictors are statistically meaningful but not good enough for DRI estimation in practice. Moreover, multiple regression, artificial neural network (ANN) and hybrid genetic algorithm (GA)-ANN models were constructed to estimate DRI. Several performance indices i.e. coefficient of determination ( $\left.\mathrm{R}^{2}\right)$, root mean square error (RMSE) and variance account for (VAF) were used for evaluation of performance prediction the proposed methods. Based on these results and the use of simple ranking procedure, the best models were chosen. It was found that the hybrid GA-ANN technique can performed better in predicting DRI compared to other developed models. This is because of the fact that the proposed hybrid model can update the biases and weights of the network connection to train by ANN.

Keywords: Drilling rate index, Rock material properties, Artificial neural network, Hybrid model. 


\section{Introduction}

Drillability is defined as the resistance of rock to penetrate the rock mass by a drilling system. Drilling rate index (DRI) is one of the tool to evaluate drillability of rocks. The drilling rate index (DRI) was proposed by Selmer-Olsen and Lien (1960) in order to evaluate the drillability of rocks by percussive drilling. The influential factors on DRI can be categorized into two parts, i.e. controllable and uncontrollable parameters. Bit type and diameter, thrust, blow frequency, rotational speed and flushing are considered as controllable factors on DRI, while some other parameters, like geological conditions and rock properties are defined as uncontrollable parameters of DRI (Yarali and Kahraman 2011). Drilling has a direct and may be close relationship with the rock mass and material properties (Hoseinie et al. 2008). Strength of rock has a considerable impact on drilling thrust. Strength properties of rocks play an important role in design, safety and stability of any rock structures (Khandelwal and Ranjith, 2010; Khandelwal, 2013). Therefore, recognition the most effective parameters on DRI and subsequently proper DRI prediction would help designers to select the appropriate type of drilling system.

Many studies have been conducted in order to demonstrate the effects of rock (mass and material) properties on DRI (e.g. Wijk 1989; Karpuz et al. 1990; Kahraman 1999; Kahraman et al. 2000; Kahraman et al. 2003; Hoseinie et al. 2009; Dahl et al. 2012; Yarali and Soyer 2013; Macias et al. 2014; Tripathy et al. 2015; Ataei et al. 2015). A penetration rate model was proposed using stepwise linear regression analysis in the study conducted by Selim and Bruce (1970). Schmidt (1972) related the penetration rate with tensile strength, density, Young's modulus, Shore hardness, shear modulus, longitudinal wave velocity, compressive strength, Poisson's ratio and shear wave velocity. A rating classification for DRI prediction was established in the study carried out by Hoseinie et al. (2008). They used six rock mass properties namely Mohs hardness, grain size, uniaxial compressive strength (UCS), joint filling, joint spacing and joint dipping to predict DRI. Yarali and Kahraman (2011) proposed new relations for predicting DRI by using brittleness values of 32 different rocks. Cheniany et al. (2012) developed linear and non-linear multiple regression to estimate specific rock mass drillability (SRMD) index. In their 
models, UCS, quartz content, Schmidt hammer hardness value, joint dip, alteration and fragment size

50 (d80) were considered as predictors. Single regression models were introduced by Yarali and Soyer

51 (2013) in order to relate DRI with several properties of rocks including UCS, Brazilian tensile strength

52 (BTS), point load strength, Schmidt rebound hardness and Shore scleroscope hardness. They showed that

53 rock strength is the most effective parameter on DRI. Moein et al. (2014) measured DRI values of

54 carbonate rock in the laboratory and indicated good relationships for predicting DRI using the alteration

55 index and specific energy.

56 In the field of artificial intelligent systems, there were also several attempts by previous researchers in

57 order to predict penetration rate. An artificial neural network (ANN) approach was selected and proposed

58 for predicting penetration rate by Akin and Karpuz (2008). They concluded that their developed approach

59 can provide satisfactory results in estimating penetration rate. Arabjamaloei and Karimi Dehkordi (2012)

60 utilized adaptive neuro-fuzzy inference system (ANFIS), ANN and statistical techniques in estimating

61 penetration rate and concluded that ANN is the best model among all developed models. A penetration

62 rate model based on ANFIS was proposed in the study conducted by Basarir et al. (2014). They

63 successfully showed that ANFIS results are better than the results of statistical model. In the present

64 study, several linear and non-linear models i.e. multiple regression analysis, ANN and hybrid genetic

65 algorithm (GA)-ANN were applied and developed to predict the DRI values using strength properties of 66 rocks.

67

\section{Method}

\subsection{Artificial Neural Network}

70

71

72

In ANNs, which are function approximation tools, the process of information-transfer in the human brain is imitated. Generally, ANNs are applicable to cases in which there is very complex and nonlinear contact nature between input variable(s) or predictor(s) and output of the system (Garrett 1994; Jahed Armaghani 
73 et al. 2015a). ANNs have been designed in many types, and the most commonly-used one is the

74 multilayer feed-forward ANN that comprises multiple layers that are connected together by a number of

75 hidden nodes (neurons) with different connection weights (Simpson 1990). For the achievement of a

76 desirable outcome, ANNs should be trained by means of some learning algorithms. For training ANNs,

77 the back-propagation (BP) algorithm is the most widely-used among other learning algorithms (Dreyfus

78 2005; Hajihassani et al. 2014; Jahed Armaghani et al. 2015b). By using BP algorithm, system error

79 between desired and predicted values can be minimized. The output of each hidden node is determined

80 subsequent to the application of a transfer function, which is mostly sigmoidal function, to the net input of

81 the hidden node. A comparison is made between the desired output (targets) and the predicted one, and

82 then the error is computed. If this error is bigger than mean square error (MSE) or root mean square error

83 (RMSE) values, the network should be propagated back for adjusting the connection weights. Figure 1

84 shows structure of BP ANN algorithm with one hidden layer.

85
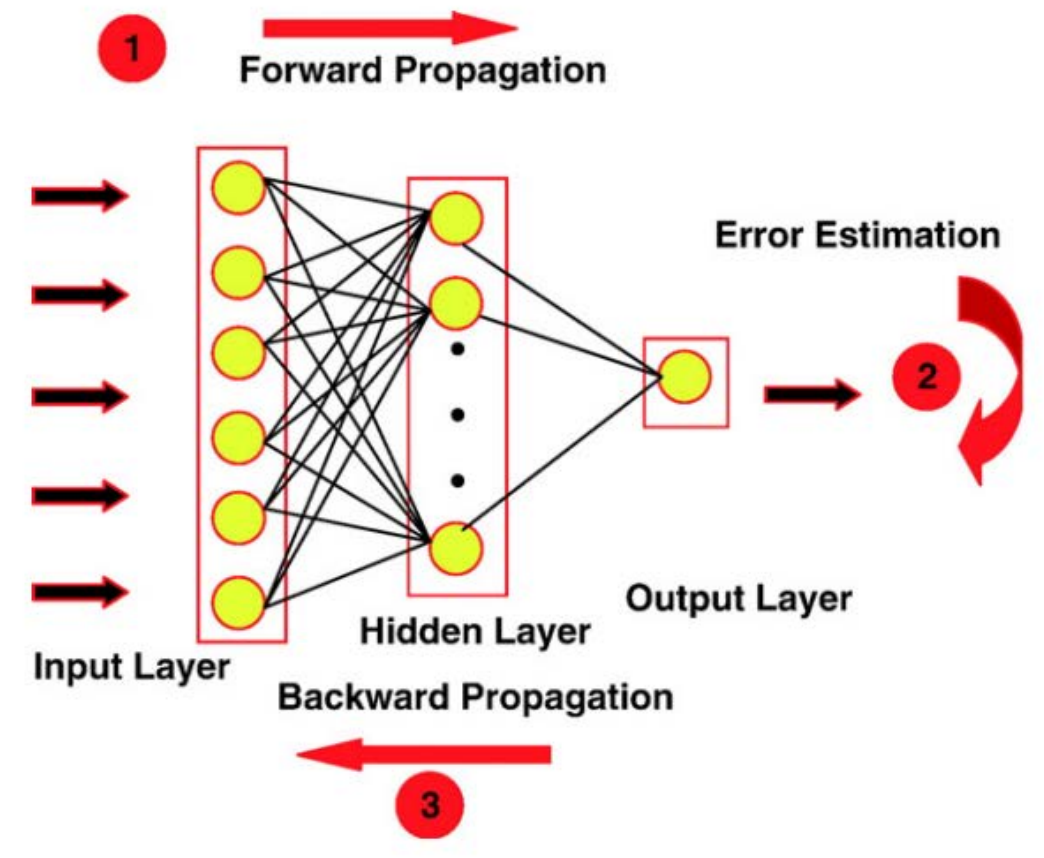


\subsection{Genetic Algorithm}

89 Genetic algorithm (GA) which was developed by Holland (1975) is considered as an optimization

90 technique. This algorithm mimics the natural selection mechanism and the biological species evolution.

91 To advance, in each decision variable, objective function evaluation is needed by GA. This is because the

92 stochastic-based technique of GA does not need any specific information for guiding the search

93 (Chipperfield et al. 2006).

94 Generally, in GA, there are populations of individuals that are known as candidate solutions; each

95 individual gradually converges over time to an optimal solution. Each candidate solution is denoted by a

96 linear string that consists of chromosomes represented by 0s and 1s. Total solutions form the population

97 size together with the optimization process of each iteration is known as a generation. In GA, for the creation of the next generation, three basic genetic operators i.e. reproduction, cross-over, and mutation

99 should be applied. The first operator or reproduction is defined as a process through which the best chromosomes are selected according to their scaled values with considering the given criteria of fitness,

101 and then the selected chromosomes are directly transferred to the next generation. Through the cross over 102 operator, offspring or new individuals are produced through combining particular parts of individuals 103 (parent). Recombination is done through several ways, including single-point cross over and two-point 104 cross over. Nevertheless, during the process of cross over, a random cross over point and two parents are 105 chosen. The creation of the first offspring is through the combination of the left side genes of the first 106 parent with the right side genes of the second parent. To form the second offspring, an inverse procedure 107 is repeated (Momeni et al. 2014). Mutation is defined as a process during which a random change occurs 108 in elements of a chromosome.

109 Several studies have been conducted to enhance the performance quality and generalisation capabilities of 110 ANNs through the use of GA algorithm (e.g. Monjezi et al. 2012; Aghajanloo et al. 2013; Momeni et al. 111 2014). GA is known as stochastic search algorithm; as a result, it can be performed for adjusting the 
112 biases and weights of the ANNs to increase the performance prediction of ANNs (Momeni et al. 2014).

113 At a local minimum, by ANNs, there is normally more probability of convergence, while GA can find a

114 global minimum. So, a combination of GA and ANN model (GA-ANN model) utilizes the search

115 properties of both algorithms to enhance the network power. In this model, first, GA finds global

116 minimum in search space, and then ANN employs it to discover the best results. A hybrid GA-ANN

117 algorithm is displayed in Figure 2.

118

119

120

121

122

123

124

125

126

127

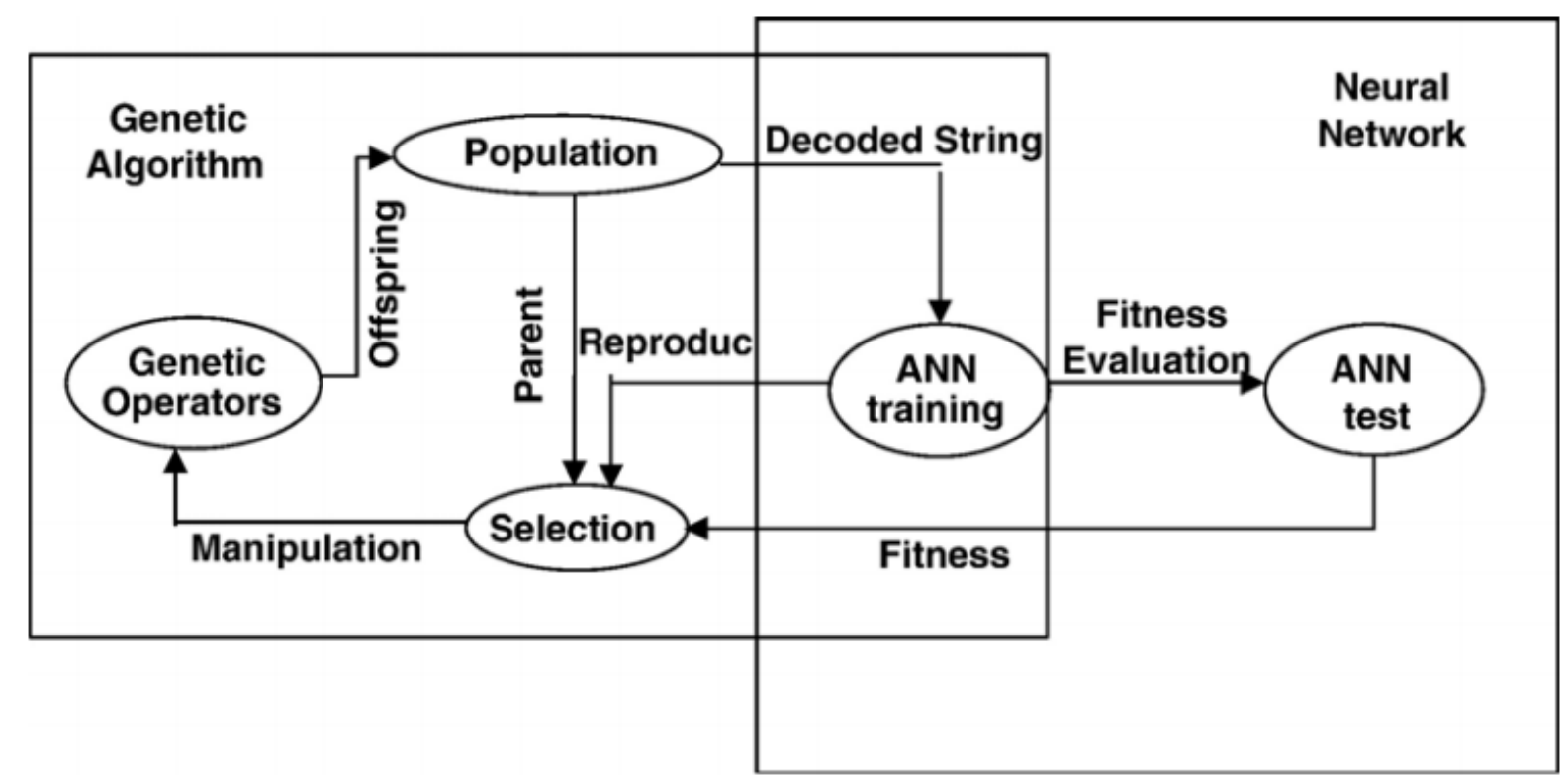

Figure 2. Combination of GA-ANN (Saemi et al. 2007)

\section{Laboratory Testing}

Rock mass samples were collected from different published literatures (Yarali and Kahraman, 2011;

Adebayo et al, 2010; Ekincioglu et al, 2013) to fulfill the aim of this research. 


\subsection{Uniaxial compressive strength}

129 Determination of UCS involves the use of a NX size (54 mm diameter) cylindrical specimen with length 130 to diameter ratio of 2.5 which is loaded axially as suggested by ISRM (1979). UCS can be calculated with 131 the help of following formula:

$$
\mathrm{UCS}=\mathrm{P} / \mathrm{A}
$$

133 where,

P - Failure load, and

A - Cross-sectional area of the cylindrical specimen

\subsection{Tensile strength}

Brazilian test is used in order to determine tensile strength in the laboratory. This test is conducted based on the fact that mostly rocks in biaxial stress fail in tension at their uniaxial tensile strength (Jaeger 1967). The test should be conducted in accordance with ISRM (1978) standard. Tensile strength can be calculated with the help of following formula:

$$
\mathrm{TS}=2 . \mathrm{P} / \pi \cdot \mathrm{d} . \mathrm{t}
$$

143 Where,

$\mathrm{d}=$ Diameter of the disc

$\mathrm{t}=$ Thickness of the disc

149 Drillability of rocks are examined on the basis of the DRI. The DRI is defined as a combination of the 150 intact rock specimen brittleness value (S20) test which was proposed by Matern and Hjelmer (1943) and 151 Sievers' J-Value (SJ) miniature drill-test which was proposed by Sievers (1950). The SJ test is considered 152 as an indirect measure of rock resistance to tool indentation (surface hardness); the brittleness value, S20, 153 is an indirect measure of rock resistance to crack growth and crushing. 


\subsubsection{The Brittleness Test}

155 In this study, S20 values were measured by using the Swedish Stamp Test (see Figure. 3). The test is 156 started by putting the rock aggregate in a mortar and then by using a $14 \mathrm{~kg}$ hammer, struck 20 times. The 157 mortar aggregate volume corresponds to that of a $0.5 \mathrm{~kg}$ aggregate with a density of 2.65 tons $/ \mathrm{m} 3$ in the 158 fraction 11.2 - $16.0 \mathrm{~mm}$. S20 equals the percentage of undersized material that passes through a $11.2 \mathrm{~mm}$ 159 mesh after the drop-test. S20 should be taken as a mean value of three or four parallel tests.

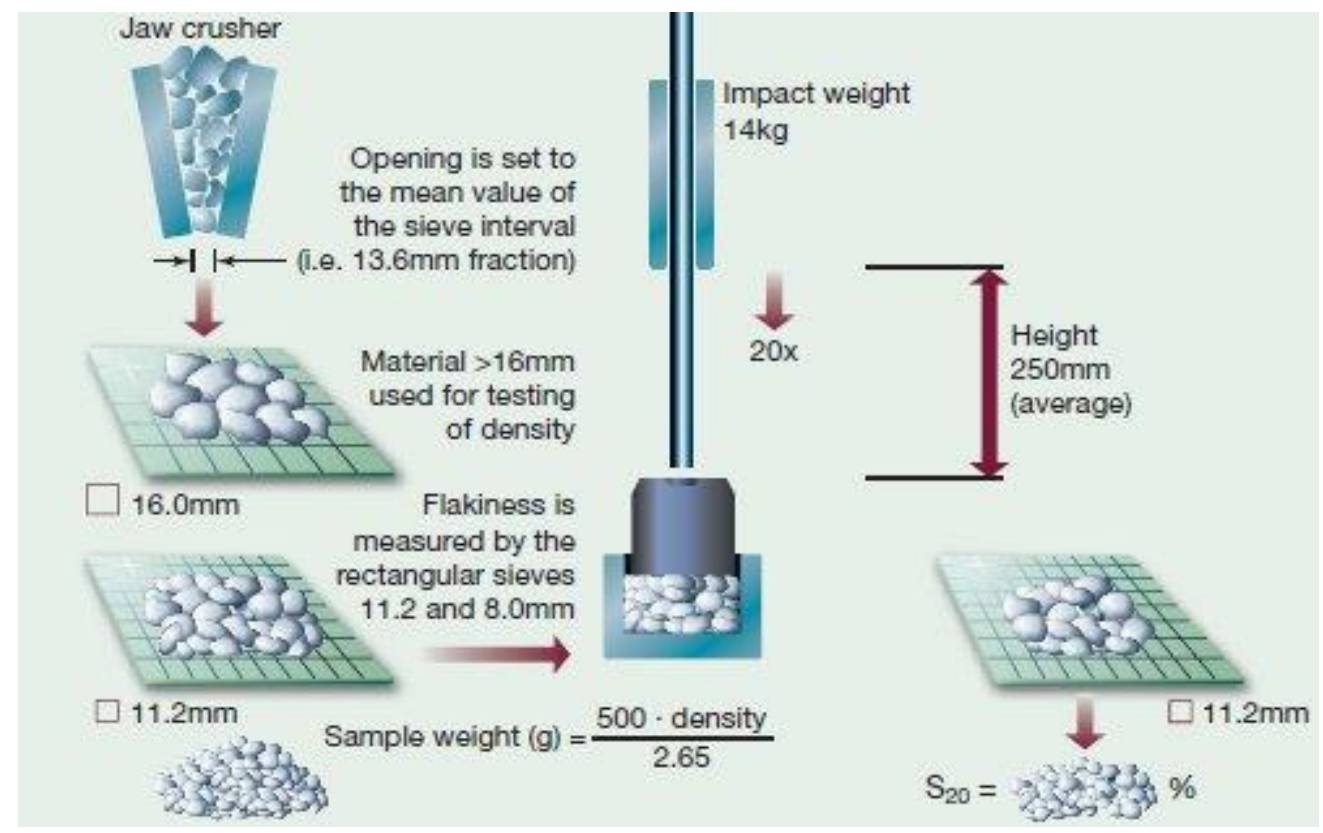

Figure 3. Outline of the brittleness test (Dahl 2003)

\subsubsection{The Sievers’ J (SJ) miniature drill test}

165 The second DRI parameter which is the SJ value, can be obtained from a miniature drill test. After 200

166 revolutions, in the rock sample, the hole depth is measured in 1/10 $\mathrm{mm}$. A mean value of four - eight test

167 holes should be used. Parallel to rock foliation, the SJ values are always measured for created holes.

168 Outline of the Sievers' J miniature drill test is shown in Figure 4. 


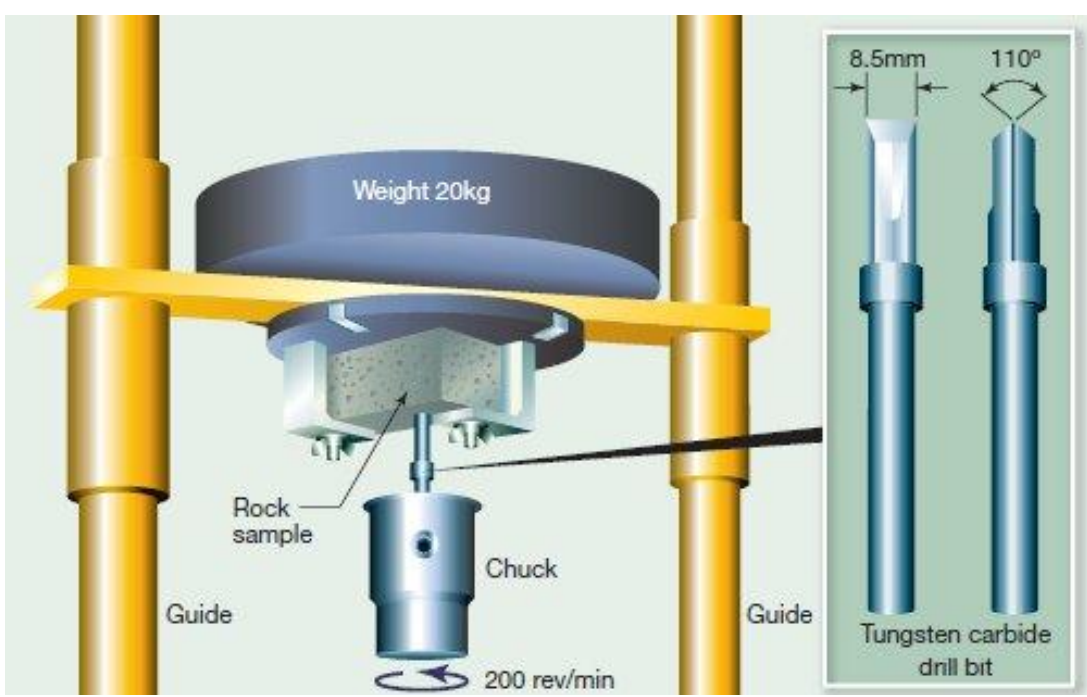

Figure. 4. Outline of the Sievers’ J miniature drill test (Dahl 2003)

171

172

\subsubsection{Assessment of DRI}

173 After measuring S20 and SJ values, DRI can be determined by using the Figure 5. Based on this figure,

174 DRI values can be determined using both brittleness and SJ values. Table 1 shows DRI classification 175 rating for various categories.

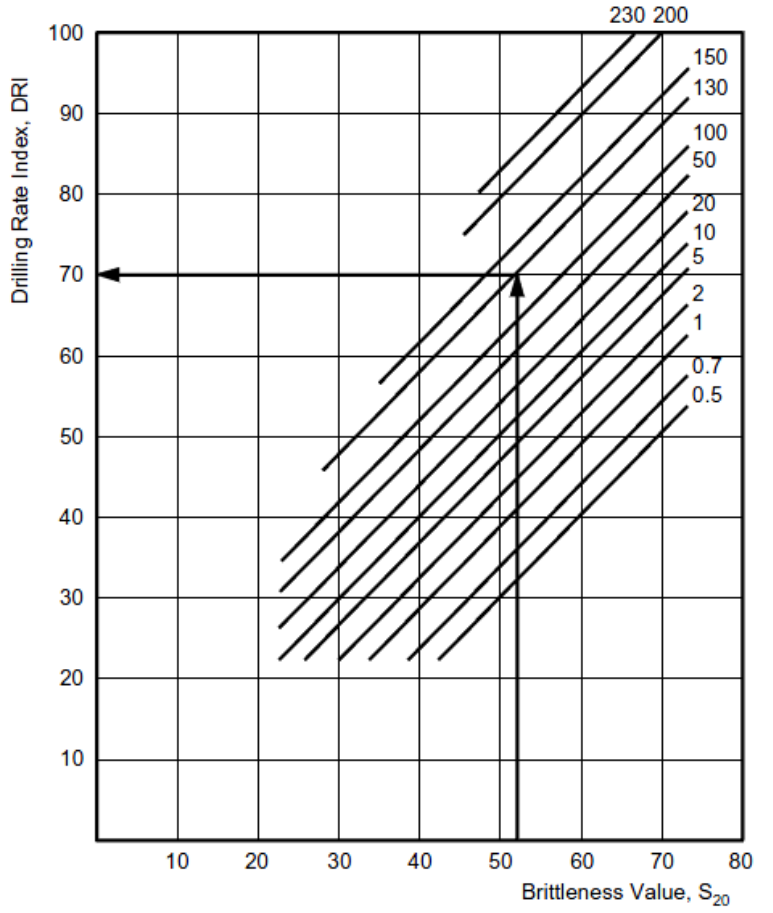

Figure. 5 The graph for determination of DRI using S20 and SJ (Bruland 1998) 


\begin{tabular}{|l|l|l|}
\hline S. No. & Category & DRI \\
\hline 1 & Extremely low & 21 \\
\hline 2 & Very low & 28 \\
\hline 3 & Low & 37 \\
\hline 4 & Medium & 49 \\
\hline 5 & High & 65 \\
\hline 6 & Very high & 86 \\
\hline 7 & Extremely high & 114 \\
\hline
\end{tabular}

\section{DRI Prediction}

181 In order to solve the engineering problem, simple regression equations are conducted in the first step. The 182 used parameters and their categories and ranges are shown in Table 2. Based on this table, UCS and BTS 183 were considered as model inputs in this study to predict DRI.

Table 2 Basic statistical description of input and output parameters

\begin{tabular}{lcccccc}
\hline Parameter & Unit & Category & Symbol & Min & Max & Mean \\
\hline Uniaxial compressive strength & MPa & Input & UCS & 28.6 & 182.1 & 95.5 \\
Brazilian tensile strength & MPa & Input & BTS & 2.57 & 17.07 & 8.68 \\
Driling rate index & - & Output & DRI & 22 & 86 & 55.26 \\
\hline
\end{tabular}

186 The simple regression analyses were performed between the DRI and predictor parameters i.e. UCS and 187 BTS. The obtained results from simple regression analysis are not good enough to be utilized to solve the 188 problem. Due to this reason, to obtain the better model for prediction of DRI, multiple regression 189 analysis, ANN and hybrid GA-ANN techniques were also conducted using established dataset. The 190 procedure of each modelling technique was described in the following sections. 


\subsection{Simple Regression}

193 In order to examine the effect of input parameters, the simple regression analyses were constructed 194 between the DRI and other mentioned parameters including UCS and BTS. Subsequently, new equations 195 introduced for estimation of DRI. In order to obtain equations with higher performance capacity, various 196 simple regression analyses such as; linear, exponential, power and logarithmic were performed. The 197 selected equations to predict DRI using UCS and BTS are presented in Equations 3 and 4, respectively.

$$
\begin{array}{ll}
\mathrm{DRI}=-26.96 \times \ln (\mathrm{UCS})+176.29 & \left(\mathrm{R}^{2}=0.396\right) \\
\mathrm{DRI}=-31.15 \times \ln (\mathrm{UCS})+120.86 & \left(\mathrm{R}^{2}=0.411\right)
\end{array}
$$

200 The reliability of the developed relationships was evaluated by comparing the obtained coefficient of 201 determination $\left(\mathrm{R}^{2}\right)$ values for each analysis. As it can be seen in Equations 3 and 4, the logarithmic 202 relationships give the best relatively results in estimating DRI among all utilized-equation types. $\mathrm{R}^{2}$ 203 values of 0.396 and 0.411 were obtained for predicting DRI considering UCS and BTS data, respectively. 204 The purposed relationships between the DRI and input parameters i.e. UCS and BTS are given in Figures 2056 and 7. The results indicated that the relations between the input parameters and DRI are meaningful but 206 not good enough for estimation of the DRI in practice. These relationships indicated that maybe multi207 inputs are required to predict the DRI, so, various modelling techniques namely multiple regression 208 analysis, ANN and GA-ANN were also constructed. 


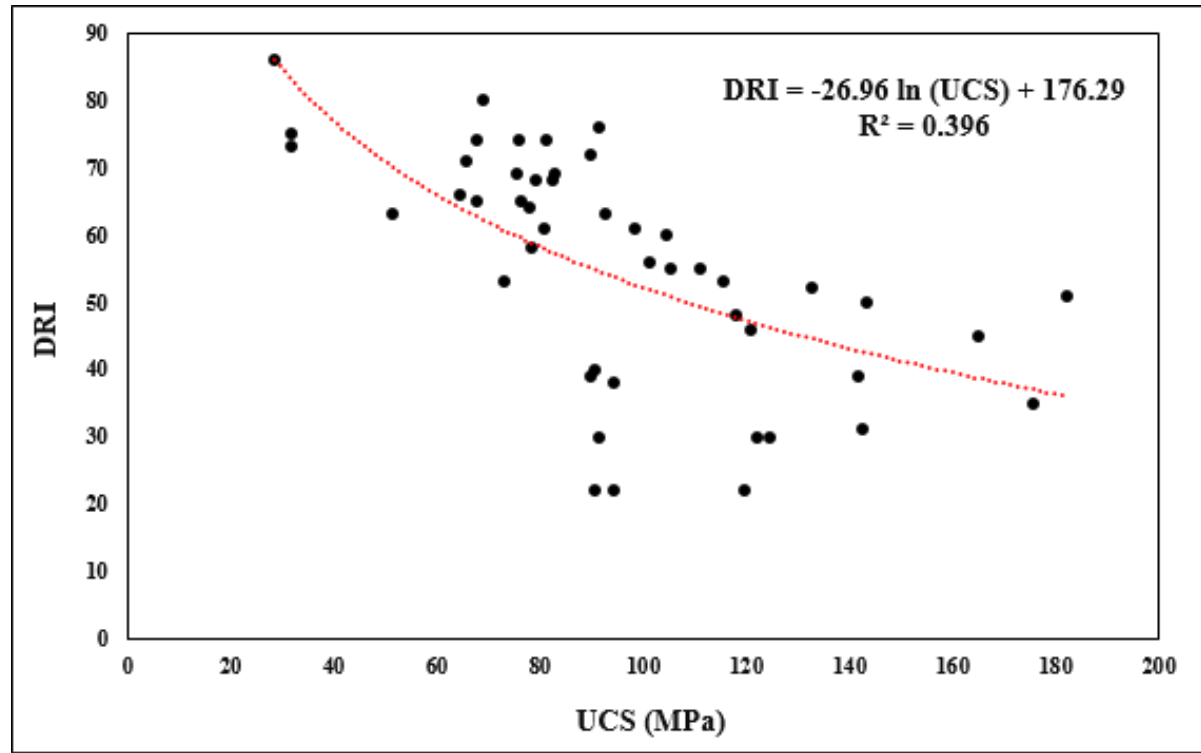

Figure 6. Relationship between measured DRI and UCS values

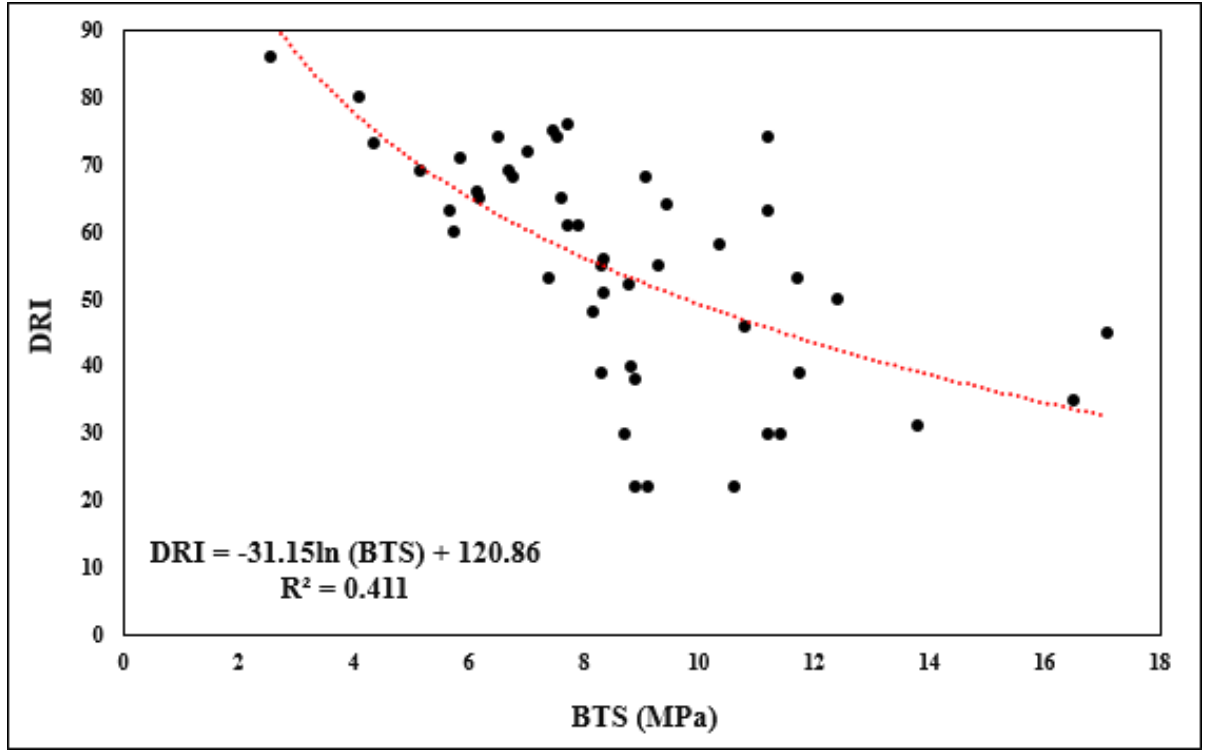

Figure 7. Relationship between measured DRI and BTS values

\subsection{Multiple Regression}

215 The multiple regression (MR) technique aims at determining the values of parameters for a function that 216 causes the function to best fit a provided set of data observations. The function is a linear (straight-line) 
217 equation in this technique. In cases where more than one independent variable exists, MR is employed in 218 order to achieve the best-fit equation. MR can solve the engineering problems through performing a least 219 squares fit. By employing this techniques, some coefficients are suggested by means of the backslash 220 operator (Khandelwal and Monjezi 2013). The MR equation type is presented as follows (Jahed 221 Armaghani et al. 2015c):

$$
y=a+b_{1} x_{1}+b_{2} x_{2}+b_{3} x_{3}+\cdots+b_{n} x_{n}
$$

223 where,

$x_{1}, x_{2}, x_{3}, \ldots, x_{n}$ are independent variables,

$b_{1}, b_{2}, b_{3}, \ldots, b_{n}$ are coefficients of independent variables, and

To predict DRI using MR technique, actual DRI values are considered to be the product of the 2 input parameters namely UCS and BTS. As a first step of MR modelling, all data should be normalized considering the below equation:

Where,

Xnorm is the normalized value of the measured parameters, parameters, respectively.

Afterwards, 5 datasets were chosen randomly to train and test for proposing MR models to evaluate the capability of the purposed model for estimation of the DRI as suggested by Zorlu et al. (2008), Yagiz et (Nelson and Illingworth 1990) of whole datasets were recommended for testing of the system. Based on above discussion, $80 \%$ (38 datasets) of whole datasets (47 datasets) was chosen randomly for developing 
the models, whereas the remained 20\% (9 datasets) of data was assigned for testing. It should be noted

241 that, an ANN code was used for the selection of the random data. Using the built datasets, five multiple

242 input equations were developed as shown in Table 3.

243 It is concluded that, the $\mathrm{R}^{2}$ values range from 0.391 to 0.451 for training and 0.325 to 0.760 for testing of

244 the MR models. In these models, UCS and BTS were considered as inputs and then, the DRI was

245 estimated as function of them. As a result, it is found that there is no salient difference among the

246 developed models. More details regarding evaluation of the developed MR equations are given later. Note

247 that, simple and MR regression analysis were performed using statistical software package of SPSS

248 version 16 (SPSS 2007).

Table 3 MR equations together with the coefficient of correlation for testing and training

\begin{tabular}{cccc}
\hline $\begin{array}{c}\text { Dataset } \\
\text { No. }\end{array}$ & Developed Relationship & Training & Testing \\
& & $\mathbf{R}^{2}$ & $\mathbf{R}^{2}$ \\
\hline 1 & DRI $=-0.342 \times \mathrm{UCS}-0.451 \times \mathrm{BTS}+0.845$ & 0.403 & 0.714 \\
2 & $\mathrm{DRI}=-0.638 \times \mathrm{UCS}-0.315 \times \mathrm{BTS}+0.927$ & 0.451 & 0.325 \\
3 & $\mathrm{DRI}=-0.370 \times \mathrm{UCS}-0.447 \times \mathrm{BTS}+0.892$ & 0.391 & 0.501 \\
4 & $\mathrm{DRI}=-0.391 \times \mathrm{UCS}-0.493 \times \mathrm{BTS}+0.898$ & 0.430 & 0.344 \\
5 & $\mathrm{DRI}=-0.406 \times \mathrm{UCS}-0.447 \times \mathrm{BTS}+0.879$ & 0.398 & 0.760 \\
\hline
\end{tabular}

\subsection{ANN Modelling}

253 In the ANN modeling, the same datasets utilized in the multiple regression part were performed. As 254 mentioned by Kanellopoulas and Wilkinson (1997) and Hush (1989), ANN ability is directly related to its 255 architecture. So, to design a desirable ANN model, determining the optimal architecture is needed. As a 256 well-known fact, architecture of an ANN model is defined as the number of hidden layer or layers and the 257 number of neuron or neurons in each hidden layer. Based on several scholars (e.g. Hecht-Nielsen 1987; 
Hornik et al. 1989), hidden layer equal to 1 can approximate any complicated function. Then, hidden layer $=1$ was chosen to construct the ANN networks. Additionally, Table 4 presents some of the available proposed equations for determining the number of neuron(s) together with their references. According to this table and considering $\mathrm{N}_{\mathrm{i}}=2$ and $\mathrm{N}_{\mathrm{o}}=1$, a range of 1-5 should be utilized in the hidden layer.

Table 4 The proposed number of neuron for hidden layer (Sonmez et al. 2006)

\begin{tabular}{ll}
\hline Heuristic & Reference \\
\hline$\leq 2 \times N_{\mathrm{i}}+1$ & Hecht-Nielsen (1987), Caudill (1988) \\
$\left(N_{i}+N_{0}\right) / 2$ & Ripley (1993) \\
$\frac{2+N_{0} \times N_{i}+0.5 N_{0} \times\left(N_{0}{ }^{2}+N_{i}\right)-3}{N_{i}+N_{0}}$ & \\
$2 N_{i} / 3$ & Paola (1994) \\
$\sqrt{N_{i} \times N_{0}}$ & Wang (1994) \\
$2 N_{i}$ & Masters (1994) \\
\hline \multicolumn{2}{c}{$\mathrm{N}_{\mathrm{i}}$ : number of input neuron, $\mathrm{N}_{0}$ : number of output neuron. }
\end{tabular}

264 To determine the optimum number of neurons in the hidden layer, various ANN networks were modelled using one hidden layer and number of hidden neurons in the range of 1 to 5 . The relevant results in terms of $\mathrm{R}^{2}$ and RMSE can be seen in Tables 5 and 6, respectively. According to these tables, considering

267 average $\mathrm{R}^{2}$ and RMSE values of both training and testing datasets, model No. 3 with hidden neurons of 3 outperforms the other ANN models. Therefore, 3 was selected as number of hidden neuron in constructing ANN models in this study. Levenberg-Marquardt (LM) learning algorithm was used in constructing ANN models. The efficiency of the LM algorithm in comparison with the other conventional

271 gradient descent techniques has been highlighted in the study conducted by Hagan and Menhaj (1994).

272 ANN results of model No. 3 (all five iterations) were considered as the best ANN results for predicting

273 DRI. More explanations regarding the selecting the best ANN network are given later. 


\begin{tabular}{|c|c|c|c|c|c|c|c|c|c|c|c|c|c|}
\hline \multirow{4}{*}{$\begin{array}{c}\text { Model } \\
\text { No. }\end{array}$} & \multirow{4}{*}{$\begin{array}{l}\text { Nodes } \\
\text { in } \\
\text { hidden } \\
\text { layers }\end{array}$} & \multicolumn{12}{|c|}{ Obtained Results of Network } \\
\hline & & \multirow{2}{*}{\multicolumn{2}{|c|}{$\frac{\text { Run } 1}{\mathbf{R}^{2}}$}} & \multirow{2}{*}{\multicolumn{2}{|c|}{$\frac{\text { Run } 2}{\mathbf{R}^{2}}$}} & \multirow{2}{*}{\multicolumn{2}{|c|}{$\frac{\text { Run } 3}{\mathbf{R}^{2}}$}} & \multirow{2}{*}{\multicolumn{2}{|c|}{$\begin{array}{c}\text { Run } 4 \\
R^{2}\end{array}$}} & \multirow{2}{*}{\multicolumn{2}{|c|}{$\frac{\text { Run } 5}{\mathbf{R}^{2}}$}} & \multirow{2}{*}{\multicolumn{2}{|c|}{$\begin{array}{c}\text { Average } \\
\mathbf{R}^{2}\end{array}$}} \\
\hline & & & & & & & & & & & & & \\
\hline & & $\begin{array}{c}\text { Train } \\
\text { ing }\end{array}$ & $\begin{array}{c}\text { Testi } \\
\text { ng }\end{array}$ & $\begin{array}{c}\text { Train } \\
\text { ing }\end{array}$ & $\begin{array}{c}\text { Testin } \\
\text { g }\end{array}$ & $\begin{array}{c}\text { Train } \\
\text { ing }\end{array}$ & $\begin{array}{c}\text { Testin } \\
\text { g }\end{array}$ & $\begin{array}{c}\text { Train } \\
\text { ing }\end{array}$ & $\begin{array}{l}\text { Testi } \\
\text { ng }\end{array}$ & $\begin{array}{c}\text { Train } \\
\text { ing }\end{array}$ & $\begin{array}{l}\text { Testi } \\
\text { ng }\end{array}$ & $\begin{array}{c}\text { Train } \\
\text { ing }\end{array}$ & $\begin{array}{l}\text { Testin } \\
\mathbf{g}\end{array}$ \\
\hline 1 & 1 & 0.773 & 0.298 & 0.812 & 0.183 & 0.769 & 0.429 & 0.814 & 0.337 & 0.787 & 0.404 & 0.791 & 0.330 \\
\hline 2 & 2 & 0.801 & 0.348 & 0.823 & 0.581 & 0.826 & 0.654 & 0.830 & 0.638 & 0.839 & 0.674 & 0.824 & 0.579 \\
\hline 3 & 3 & 0.855 & 0.824 & 0.827 & 0.839 & 0.835 & 0.838 & 0.819 & 0.807 & 0.859 & 0.821 & 0.839 & 0.826 \\
\hline 4 & 4 & 0.841 & 0.811 & 0.837 & 0.821 & 0.801 & 0.792 & 0.822 & 0.81 & 0.833 & 0.832 & 0.827 & 0.813 \\
\hline 5 & 5 & 0.845 & 0.834 & 0.811 & 0.838 & 0.817 & 0.820 & 0.829 & 0.815 & 0.842 & 0.809 & 0.829 & 0.823 \\
\hline
\end{tabular}

279

280 Table 6 RMSE values of the constructed ANN models to predict DRI for selecting the optimum number of hidden node

\begin{tabular}{|c|c|c|c|c|c|c|c|c|c|c|c|c|c|}
\hline \multirow{4}{*}{$\begin{array}{l}\text { Model } \\
\text { No. }\end{array}$} & \multirow{4}{*}{$\begin{array}{l}\text { Nodes } \\
\text { in } \\
\text { hidden } \\
\text { layers }\end{array}$} & \multicolumn{12}{|c|}{ Obtained Results of Network } \\
\hline & & \multirow{2}{*}{\multicolumn{2}{|c|}{$\begin{array}{c}\text { Run } 1 \\
\text { RMSE }\end{array}$}} & \multirow{2}{*}{\multicolumn{2}{|c|}{$\begin{array}{c}\text { Run } 2 \\
\text { RMSE }\end{array}$}} & \multirow{2}{*}{\multicolumn{2}{|c|}{$\begin{array}{c}\text { Run } 3 \\
\text { RMSE }\end{array}$}} & \multirow{2}{*}{\multicolumn{2}{|c|}{$\begin{array}{c}\text { Run } 4 \\
\text { RMSE }\end{array}$}} & \multirow{2}{*}{\multicolumn{2}{|c|}{$\begin{array}{c}\text { Run } 5 \\
\text { RMSE }\end{array}$}} & \multirow{2}{*}{\multicolumn{2}{|c|}{$\begin{array}{c}\text { Average } \\
\text { RMSE }\end{array}$}} \\
\hline & & & & & & & & & & & & & \\
\hline & & $\begin{array}{c}\text { Train } \\
\text { ing }\end{array}$ & $\begin{array}{c}\text { Testi } \\
\text { ng }\end{array}$ & $\begin{array}{c}\text { Train } \\
\text { ing }\end{array}$ & $\begin{array}{c}\text { Testin } \\
\mathbf{g}\end{array}$ & $\begin{array}{c}\text { Train } \\
\text { ing }\end{array}$ & $\begin{array}{c}\text { Testin } \\
\mathbf{g}\end{array}$ & $\begin{array}{c}\text { Train } \\
\text { ing }\end{array}$ & $\begin{array}{c}\text { Testi } \\
\text { ng }\end{array}$ & $\begin{array}{c}\text { Train } \\
\text { ing }\end{array}$ & $\begin{array}{c}\text { Testi } \\
\text { ng }\end{array}$ & Train & Test \\
\hline 1 & 1 & 0.135 & 0.319 & 0.137 & 0.274 & 0.155 & 0.251 & 0.149 & 0.231 & 0.132 & 0.244 & 0.142 & 0.264 \\
\hline 2 & 2 & 0.134 & 0.460 & 0.148 & 0.252 & 0.146 & 0.226 & 0.140 & 0.211 & 0.144 & 0.144 & 0.142 & 0.259 \\
\hline 3 & 3 & 0.157 & 0.106 & 0.157 & 0.090 & 0.130 & 0.122 & 0.144 & 0.108 & 0.106 & 0.088 & 0.139 & 0.103 \\
\hline 4 & 4 & 0.162 & 0.111 & 0.172 & 0.096 & 0.122 & 0.134 & 0.139 & 0.129 & 0.145 & 0.110 & 0.148 & 0.116 \\
\hline 5 & 5 & 0.160 & 0.092 & 0.170 & 0.103 & 0.133 & 0.125 & 0.141 & 0.131 & 0.128 & 0.134 & 0.146 & 0.117 \\
\hline
\end{tabular}

\section{$283 \quad$ 4.4 GA-ANN Modelling}

284 As mentioned before, GA can efficiently improve the ANN performance and remove its limitations (e.g.

285 Lee et al. 1991; Majdi and Beiki 2010; Rashidian and Hassanlourad 2013). The most frequently-cited

286 advantage of GAs is the capability of these algorithms in escaping from being trapped in a local optimum

287 (Chambers 2010). Chambers (2010) showed that with the use of a GA or at least a hybrid GA, an

288 appropriate objective function can be freely selected. It can be concluded that the network connection 

model can be referred to (Hagan and Menhaj 1994) for more details.

291

292

293

294

295

296

297

298

299

300

301

302

303

304

To propose hybrid GA-ANN model for DRI prediction, the most influential GA parameters should be designed. To do this, several parametric investigations were carried out to find optimum GA parameters. In the hybrid GA-ANN model, the mutation probability was set to $25 \%$ of the population size; whereas the percentage of recombination was fixed at $9 \%$ and value of $1 \%$ was applied as utilized by Momeni et al. (2014). The single point cross-over was used with 70\%possibility. Numerous selection methods have been proposed in the literatures regarding cross-over operation; however, the tournament selection method was employed to generate two offspring from two parents (Momeni et al. 2014). It should be mentioned that the mutation probability and cross-over possibility were determined using trial-and-error method.

Finding the best population size is the next step of the hybrid GA-ANN. In this regard, several GA-ANN models were built with population sizes in range of 25 to 600 as shown in Table 7 . In these models, the suggested ANN architecture and maximum generation of 100 were utilized. In the Table 7 , the $\mathrm{R}^{2}$ and RMSE values were tabulated for training and testing datasets of each model. Generally, increment in population size causes the increase in $\mathrm{R}^{2}$ values and decrease in RMSE values. Since selection of the best model is too difficult, a simple ranking method proposed by Zorlu et al. (2008) was performed to obtain the optimum population size. Based on this method, each performance index was ordered in its class and the best performance index was assigned the highest rating. As an example, $\mathrm{R}^{2}$ values of $0.426,0.437$, 0.425, 0.386, 0.420, 0.372, 0.443, 0.480, 0.661, 0.753, 0.842, $0.921,0.927$ and 0.931 were obtained for training datasets of models 1 to 14, respectively. Hence, their ratings were assigned as 5, 6, 4, 1, 3, 2, 7, 8, 9, 10, 11, 12, 13 and 14, respectively. This procedure was repeated for results of RMSE as well. After this process, the obtained ratings of performance indices for training and testing datasets were summed up in each model as shown in the last column of Table 7 (total rank). Based on obtained total rank values, 
313 model No. 12 can provide higher performance capacity compared to other models. Therefore, population

314 size of 500 was chosen in modeling of GA-ANN technique.

Table 7 Effects of population size on network performance

\begin{tabular}{|c|c|c|c|c|c|c|c|c|c|c|}
\hline \multirow{3}{*}{$\begin{array}{l}\text { Model } \\
\text { No. }\end{array}$} & \multirow{3}{*}{$\begin{array}{c}\text { Population } \\
\text { Size }\end{array}$} & \multicolumn{4}{|c|}{ Network Result } & \multicolumn{4}{|c|}{ Ranking } & \multirow{3}{*}{$\begin{array}{l}\text { Total } \\
\text { Rank }\end{array}$} \\
\hline & & \multicolumn{2}{|c|}{ Train } & \multicolumn{2}{|c|}{ Test } & \multicolumn{2}{|c|}{ Train } & \multicolumn{2}{|c|}{ Test } & \\
\hline & & $\mathbf{R}^{2}$ & RMSE & $\mathbf{R}^{2}$ & RMSE & $\mathbf{R}^{2}$ & RMSE & $\mathbf{R}^{2}$ & RMSE & \\
\hline 1 & 25 & 0.426 & 0.200 & 0.223 & 0.217 & 5 & 5 & 1 & 2 & 13 \\
\hline 2 & 50 & 0.437 & 0.194 & 0.561 & 0.181 & 6 & 7 & 6 & 4 & 23 \\
\hline 3 & 75 & 0.425 & 0.182 & 0.341 & 0.253 & 4 & 8 & 2 & 1 & 15 \\
\hline 4 & 100 & 0.386 & 0.195 & 0.486 & 0.213 & 1 & 6 & 4 & 3 & 14 \\
\hline 5 & 150 & 0.420 & 0.201 & 0.506 & 0.175 & 3 & 4 & 5 & 5 & 17 \\
\hline 6 & 200 & 0.372 & 0.207 & 0.658 & 0.153 & 2 & 2 & 9 & 7 & 20 \\
\hline 7 & 250 & 0.443 & 0.203 & 0.456 & 0.158 & 7 & 3 & 3 & 6 & 19 \\
\hline 8 & 300 & 0.480 & 0.182 & 0.632 & 0.147 & 8 & 8 & 8 & 9 & 33 \\
\hline 9 & 350 & 0.661 & 0.171 & 0.592 & 0.152 & 9 & 9 & 7 & 8 & 33 \\
\hline 10 & 400 & 0.753 & 0.154 & 0.778 & 0.137 & 10 & 10 & 10 & 11 & 41 \\
\hline 11 & 450 & 0.842 & 0.148 & 0.851 & 0.131 & 11 & 11 & 11 & 13 & 46 \\
\hline 12 & 500 & 0.921 & 0.139 & 0.932 & 0.122 & 12 & 13 & 14 & 14 & 53 \\
\hline 13 & 550 & 0.927 & 0.140 & 0.921 & 0.135 & 13 & 12 & 13 & 12 & 50 \\
\hline 14 & 600 & 0.931 & 0.138 & 0.913 & 0.144 & 14 & 14 & 12 & 10 & 50 \\
\hline
\end{tabular}

316

317 Determination of maximum number of generation $\left(G_{\max }\right)$ is the next step of GA-ANN modelling

318 procedure. To recognize the effect of $G_{\max }$ on the network’s performance, one more parametric study was

319 conducted. The number of generation was set to be 500 in order to determine the optimum number of

320 generation. To do this, 14 models presented in Table 7 were constructed again using the mentioned

321 maximum generation number (500). Figure 8 shows the importance of the number of generation to the

322 network performance for predicting DRI. As displayed in this figure, there is no changes in the network

323 performance (RMSE) after generation number $=300$. Hence, the optimum number of generation was set

324 to be 300 in design of GA-ANN models. It is worth mentioning that in determining number of generation, 325 the other mentioned network parameters were kept constant. 


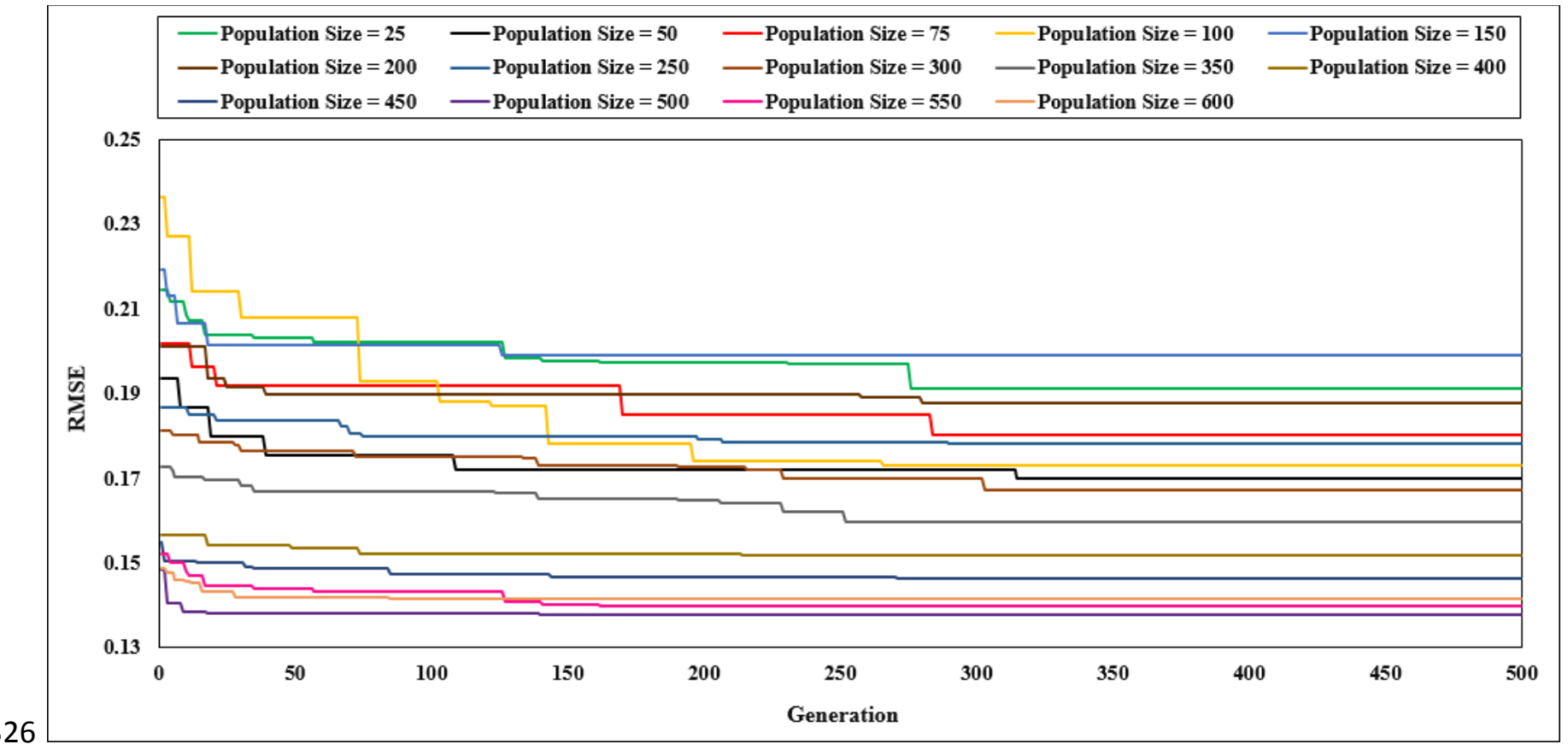

Figure 8. The effect of the number of generation on the network performance

328 In the final step of hybrid GA-ANN modelling, by using three different factors namely the suggested 329 ANN structure $(2 \times 3 \times 1), 5$ randomly selected datasets, and determined GA parameters, five hybrid 330 models were constructed. Evaluation of the obtained results of the hybrid models together with its 331 discussion will be given later.

\section{Evaluation of the Results}

334 In this study, several techniques i.e. multiple regression, ANN and GA-ANN were applied and proposed 335 for DRI prediction. Here, all 47 datasets were randomly selected to 5 datasets (to training and testing 336 purposes) for developing the linear and non-linear models. For evaluation of the prediction performance, 337 several performance indices including $\mathrm{R}^{2}$, amount of variance account for (VAF) and RMSE were considered and computed: 


$$
\mathrm{R}^{2}=1-\frac{\sum_{i=1}^{N}\left(y-\mathrm{y}^{\prime}\right)^{2}}{\sum_{i=1}^{N}(y-\tilde{\mathrm{y}})^{2}}
$$

$$
\mathrm{VAF}=\left[1-\frac{\operatorname{var}\left(\mathrm{y}-\mathrm{y}^{\prime}\right)}{\operatorname{var}(\mathrm{y})}\right] \times 100
$$

$$
\operatorname{RMSE}=\sqrt{\frac{1}{\mathrm{~N}} \sum_{\mathrm{i}=1}^{\mathrm{N}}\left(\mathrm{y}-\mathrm{y}^{\prime}\right)^{2}}
$$

342 Where,

$y, y^{\prime}$ and $\tilde{y}$ are the measured, predicted and mean of the $y$ values respectively,

$P$ is the number of predictors.

346 Results of the mentioned indices for training and testing datasets are tabulated in Table 8. As shown in 347 this table, selecting the best model for DRI estimation is not easy. To overcome this difficulty, as 348 mentioned before, a simple ranking procedure developed by Zorlu et al. (2008) was used. A ranking value was computed and assigned for each training and testing dataset separately (see Table 8). The obtained total rank results for the developed models are shown in Table 9. Based on Table 9, model No. 4 exhibited the best performance of DRI prediction for MR technique, while models No. 5 and 1 yielded the 352 best results of ANN and GA-ANN techniques, respectively. Therefore, the hybrid GA-ANN models can 353 provide higher prediction performances in predicting DRI compared to other developed models (ANN 354 and MR). The selected MR equation (model No. 4) is shown as follows: 
Table 8 The obtained performance indices for treaining antesting and their ranges for proposed models

\begin{tabular}{|c|c|c|c|c|c|c|c|c|}
\hline Method & Model & $\mathbf{R}^{2}$ & RMSE & VAF & $\begin{array}{c}\text { Rating for } \\
\mathbf{R}^{2}\end{array}$ & $\begin{array}{c}\text { Rating for } \\
\text { RMSE }\end{array}$ & $\begin{array}{l}\text { Rating for } \\
\text { VAF }\end{array}$ & Rank value \\
\hline \multirow{10}{*}{ MR } & Training 1 & 0.403 & 0.201 & 40.304 & 3 & 4 & 3 & 10 \\
\hline & Training 2 & 0.451 & 0.205 & 45.051 & 5 & 2 & 5 & 12 \\
\hline & Training 3 & 0.391 & 0.202 & 39.065 & 1 & 3 & 1 & 5 \\
\hline & Training 4 & 0.430 & 0.199 & 43.028 & 4 & 5 & 4 & 13 \\
\hline & Training 5 & 0.398 & 0.221 & 39.750 & 2 & 1 & 2 & 5 \\
\hline & Testing 1 & 0.714 & 0.204 & 45.537 & 4 & 1 & 3 & 8 \\
\hline & Testing 2 & 0.325 & 0.185 & 0.539 & 1 & 3 & 1 & 5 \\
\hline & Testing 3 & 0.501 & 0.195 & 48.802 & 3 & 2 & 4 & 9 \\
\hline & Testing 4 & 0.344 & 0.150 & 34.134 & 2 & 4 & 2 & 8 \\
\hline & Testing 5 & 0.760 & 0.093 & 71.843 & 5 & 5 & 5 & 15 \\
\hline \multirow{10}{*}{ ANN } & Training 1 & 0.855 & 0.157 & 85.466 & 4 & 2 & 4 & 10 \\
\hline & Training 2 & 0.827 & 0.157 & 82.576 & 2 & 2 & 2 & 6 \\
\hline & Training 3 & 0.835 & 0.130 & 83.419 & 3 & 4 & 3 & 10 \\
\hline & Training 4 & 0.819 & 0.144 & 81.438 & 1 & 3 & 1 & 5 \\
\hline & Training 5 & 0.859 & 0.106 & 85.934 & 5 & 5 & 5 & 15 \\
\hline & Testing 1 & 0.824 & 0.106 & 82.316 & 3 & 3 & 3 & 9 \\
\hline & Testing 2 & 0.839 & 0.090 & 83.882 & 5 & 4 & 5 & 14 \\
\hline & Testing 3 & 0.838 & 0.122 & 82.773 & 4 & 1 & 4 & 9 \\
\hline & Testing 4 & 0.807 & 0.108 & 77.351 & 1 & 2 & 1 & 4 \\
\hline & Testing 5 & 0.821 & 0.088 & 82.061 & 2 & 5 & 2 & 9 \\
\hline \multirow{10}{*}{ GA-ANN } & Training 1 & 0.933 & 0.071 & 93.066 & 3 & 4 & 4 & 11 \\
\hline & Training 2 & 0.926 & 0.111 & 92.090 & 2 & 2 & 2 & 6 \\
\hline & Training 3 & 0.948 & 0.066 & 94.772 & 5 & 5 & 5 & 15 \\
\hline & Training 4 & 0.937 & 0.076 & 93.046 & 4 & 3 & 3 & 10 \\
\hline & Training 5 & 0.921 & 0.119 & 91.909 & 1 & 1 & 1 & 3 \\
\hline & Testing 1 & 0.940 & 0.077 & 94.037 & 3 & 3 & 4 & 10 \\
\hline & Testing 2 & 0.945 & 0.058 & 94.457 & 4 & 4 & 5 & 13 \\
\hline & Testing 3 & 0.935 & 0.090 & 92.341 & 2 & 2 & 1 & 5 \\
\hline & Testing 4 & 0.929 & 0.053 & 92.845 & 1 & 5 & 2 & 8 \\
\hline & Testing 5 & 0.946 & 0.098 & 93.636 & 5 & 1 & 3 & 9 \\
\hline
\end{tabular}

361

362

363

364

365

366

367

368

369

370 
Table 9 Obtained total rank results for the developed models

\begin{tabular}{lcc}
\hline Method & Model & Total rank \\
\hline & 1 & 18 \\
MR & 2 & 17 \\
& 3 & 14 \\
& 4 & 21 \\
& 5 & 20 \\
\hline & 1 & 19 \\
& 2 & 20 \\
ANN & 3 & 19 \\
& 4 & 9 \\
& 5 & 24 \\
\hline & & \\
GA-ANN & 1 & 21 \\
& 2 & 19 \\
& 3 & 20 \\
& 4 & 18 \\
& 5 & 12 \\
\hline
\end{tabular}

372

373 The graphs of predicted DRI using the MR, ANN and GA-ANN techniques against the measured DRI for

374 training and testing datasets are shown in Figures 9 to 11, respectively. Based on the presented figures,

375 the GA-ANN model can perform better in estimating DRI compared to other proposed models. Based on

376 these figures, the $\mathrm{R}^{2}$ equal to 0.940 for testing dataset suggests the superiority of the hybrid GA-ANN

377 model, while these values are 0.821 and 0.344 for ANN and MR models, respectively. This shows the

378 capability of the hybrid GA-ANN technique to predict DRI. 


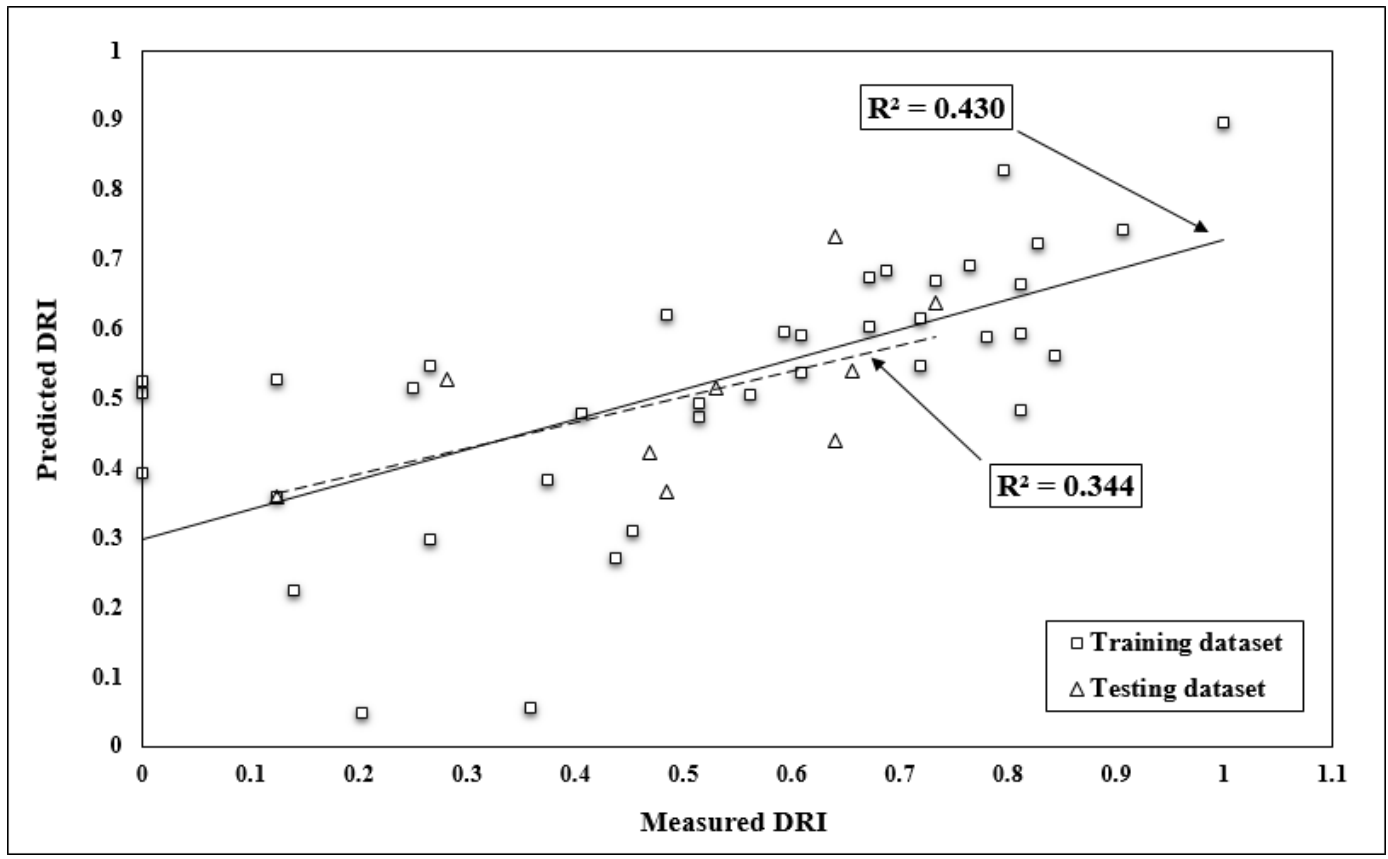

Figure 9. Predicted DRI values by MR model against the Measured DRI

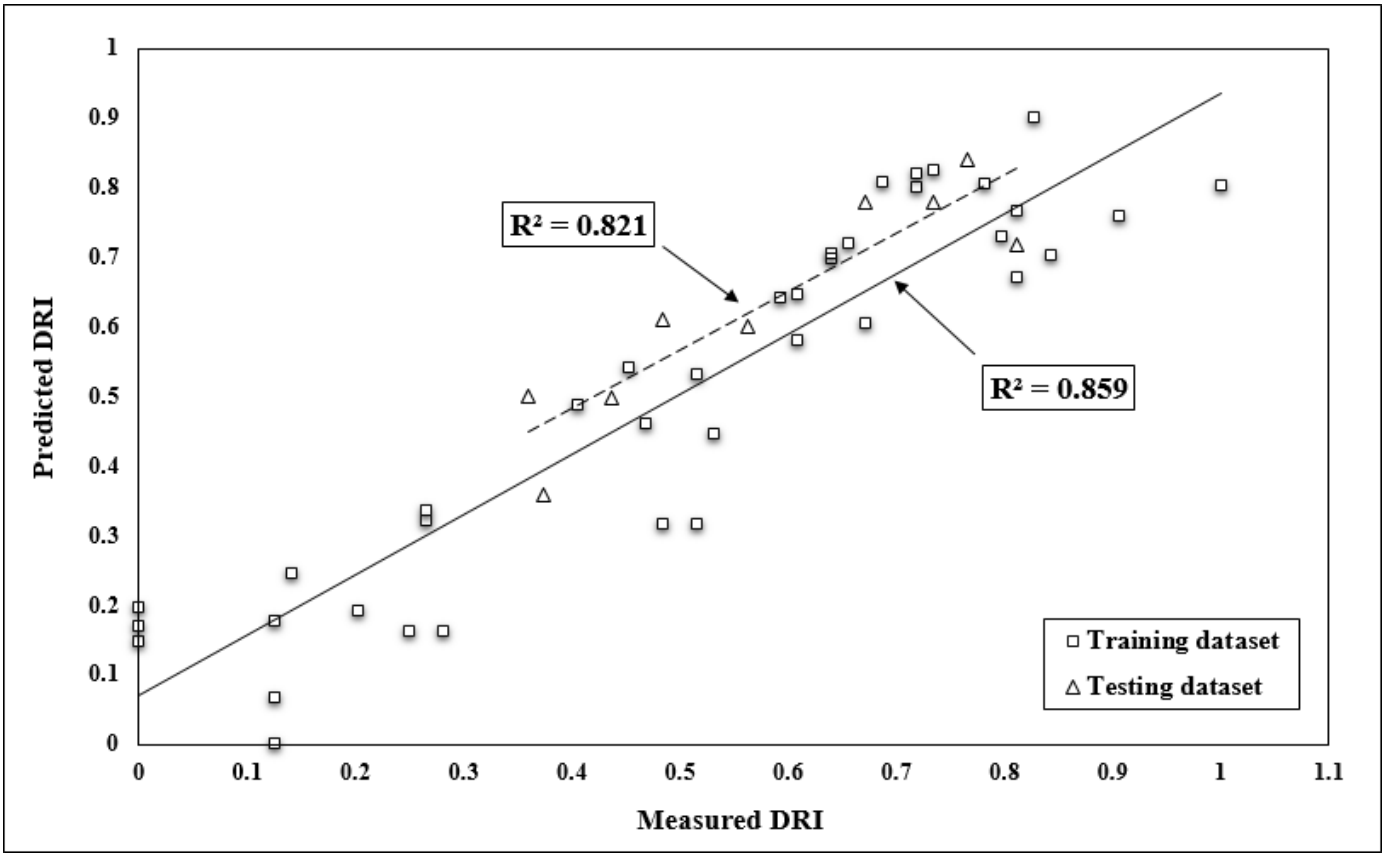

Figure 10. Predicted DRI values by ANN model against the Measured DRI 


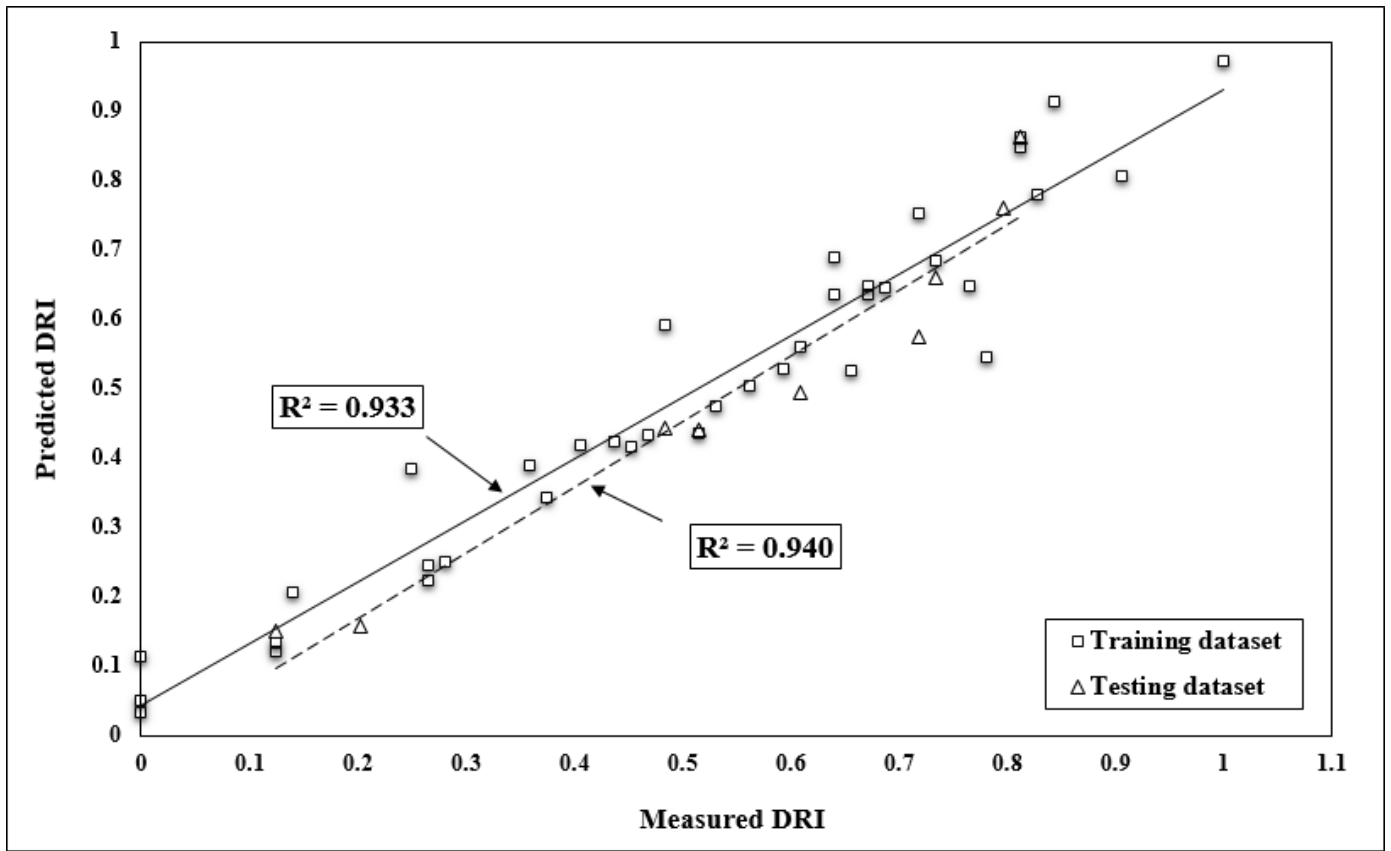

Figure 11. Predicted DRI values by GA-ANN model against the Measured DRI

\section{Sensitivity Analysis}

386 In this study, sensitivity analysis was performed to investigate the impacts of each input parameter on the 387 output(s) using the cosine amplitude method (Yang and Zang 1997). All data pairs were utilized to 388 construct a data array $X$ as follows:

$389 \quad X=\left\{x_{1}, x_{2}, x_{3}, \ldots, x_{i}, \ldots, x_{n}\right\}$

390 Variable $x_{i}$ in array $X$ is a length vector of $\mathrm{m}$ as:

$391 \quad x_{i}=\left\{x_{i 1}, x_{i 2}, x_{i 3}, \ldots, x_{i m}\right\}$

392 The strength of the relationship $\left(r_{i j}\right)$ between datasets $X_{i}$ and $X_{j}$ can be expressed as follows:

$393 \quad r_{i j}=\frac{\sum_{\mathrm{k}=1}^{\mathrm{m}} \mathrm{x}_{\mathrm{ik}} \mathrm{x}_{\mathrm{jk}}}{\sqrt{\sum_{\mathrm{k}=1}^{\mathrm{m}} \mathrm{x}^{2}{ }_{\mathrm{ik}} \sum_{\mathrm{k}=1}^{\mathrm{m}} \mathrm{x}^{2}{ }_{\mathrm{ik}}}}$ 


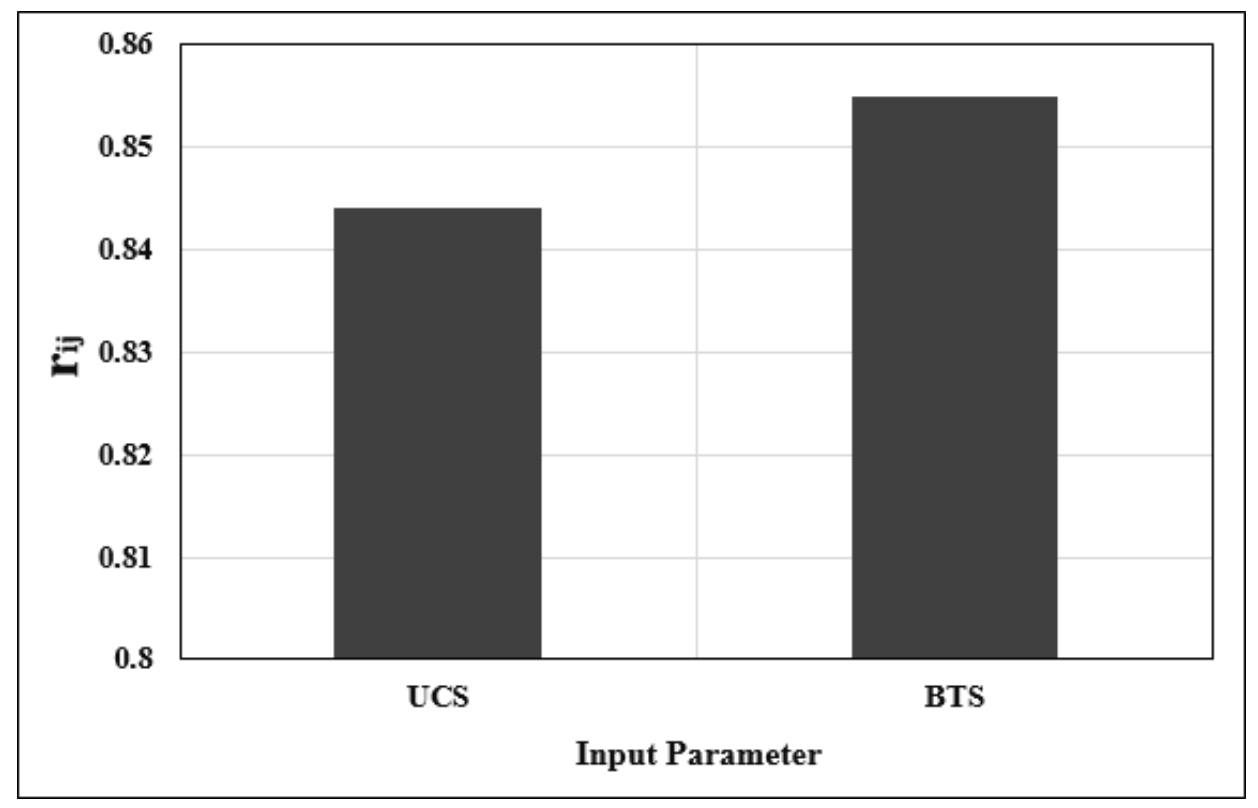

\section{Conclusions}

In this study, an attempt has been made to predict DRI by using strength properties of rock. To achieve this aim, DRI tests were conducted in the laboratory. In order to estimate DRI, two strength properties of rock namely UCS and BTS were chosen as model inputs. Based on simple regression models, the relationship between the DRI and input variables are acceptable and meaningful. Since each mentioned parameter has good relationship with the DRI, multiple regression, ANN and GA-ANN models were also generated to achieve the best accurate result.

In order to develop multiple-input models, the established datasets were divided into training and testing parts as suggested in the literature. Further, five different dataset for training and testing were established

407 randomly to obtain the best models for each modeling technique. Developed models are compared to each 408 other for choosing the best model among them. For selecting the best model, obtained $\mathrm{R}^{2}$ and total rank 
409

410 $411 \quad \mathrm{MR}\left(\mathrm{R}^{2}=0.344\right)$. Also, on taking into considering the training datasets, similar results were also obtained

$412 \quad\left(\mathrm{R}^{2}=0.430 ; 0.859 ; 0.933\right.$, respectively). It was found that the hybrid GA-ANN technique shows the best 413 result compared to other models. Additionally, results of sensitivity analysis showed that the effect of

414 BTS on DRI is slightly higher than the effect of UCS.

415

416

417

418

419

420

421

422

423

424

425

426

427

428

429

430

431

432

for each model were computed and compared. As considering the testing datasets, the prediction performance of the GA-ANN model $\left(\mathrm{R}^{2}=0.940\right)$ is higher than that of the ANN model $\left(\mathrm{R}^{2}=0.821\right)$ and

\section{References}

Adebayo B, Opafunso Z O, Akande J M (2010), Drillability and strength characteristics of selected rocks in Nigeria. AU Journal of Technology 14(1):56-60

Aghajanloo MB, Sabziparvar AA, Talaee PH (2013) Artificial neural network-genetic algorithm for estimation of crop evapotranspiration in a semi-arid region of Iran. Neural Comput Appl 23(5): 1387-1393

Akin S, Karpuz C (2008) Estimating drilling parameters for diamond bit drilling operations using artificial neural networks. Int J Geomech 8(1):68-73

Arabjamaloei R, Karimi Dehkordi B (2012) Investigation of the Most Efficient Approach of the Prediction of the Rate of Penetration. Energy Sources, Part A: Recovery, Utilization, and Environmental Effects 34(7):581-590

Ataei M, KaKaie R, Ghavidel M, Saeidi O (2015) Drilling rate prediction of an open pit mine using the rock mass drillability index. Int J Rock Mech Min Sci 73:130-138

Basarir H, Tutluoglu L, Karpuz C (2014) Penetration rate prediction for diamond bit drilling by adaptive neuro-fuzzy inference system and multiple regressions. Eng Geol 173:1-9

Bruland A (1998) Drillability Test Methods. Trondheim: NTNU

Caudill M (1988) Neural networks primer part III. Al Expert 3:53-9

Chambers LD (2010) Practical Handbook of Genetic Algorithms: Complex Coding Systems, CRC Press 
433

434

435

436

437

438

439

440

441

442

443

444

445

446

447

448

449

450

451

452

453

454

455

456

457

458

Cheniany A, Hasan KS, Shahriar K, Hamidi JK (2012) An estimation of the penetration rate of rotary drills using the Specific Rock Mass Drillability index. Int J Rock Mech Min Sci 22:187-193

Chipperfield A, Fleming P, Pohlheim H (2006) Genetic algorithm toolbox for use with MATLAB User's guide. version 1.2. University of Sheffield

Dahl F (2003) DRI, BWI, CLI Standards. NTNU, Angleggsdrift, Trondheim

Dahl F, Bruland A, Jakobsen PD, Nilsen B, Grøv E (2012) Classifications of properties influencing the drillability of rocks, based on the NTNU/SINTEF test method. Tunnel Undergr Sp Technol 28:150-158

Dreyfus G (2005) Neural Networks: Methodology and Application, Springer Berlin Heidelberg, Germany

Ekincioglu G, Altindag R, Sengun N, Demirdag S, Guney A (2013) The relationships between drilling rate index (DRI), physico-mechanical properties and specific cutting energy for some carbonate rocks, Rock Mechanics for Resources, Energy and Environment, Taylor \& Francis group, London, 867-873

Garrett J (1994) Where and why artificial neural networks are applicable in civil engineering. J Comput Civil Eng 8:129-130

Hagan MT, Menhaj MB (1994) Training feed forward networks with the Marquardt algorithm, IEEE Trans. Neural Networks 5:861-867

Hajihassani M., Jahed Armaghani D., Marto A., Tonnizam Mohamad E (2014) Ground vibration prediction in quarry blasting through an artificial neural network optimized by imperialist competitive algorithm. Bull Eng Geol Environ doi:10.1007/s10064-014-0657-x

Hecht-Nielsen R (1987) Kolmogorov’s mapping neural network existence theorem. In: Proceedings of the First IEEE International Conference on Neural Networks, San Diego, CA, USA, pp 11-14

Holland J (1975) Adaptation in Natural and Artificial Systems, The University of Michigan Press, Ann Arbor

Hornik K, Stinchcombe M, White H (1989) Multilayer feedforward networks are universal Approximators. Neural Networks 2:359-366 
Hoseinie SH, Aghababaei H, Pourrahimian Y (2008) Development of a new classification system for assessing of rock mass drillability index (RDi). Int J Rock Mech Min Sci 45:1-10

Hoseinie SH, Ataei M, Osanloo M (2009) A new classification system for evaluating rock penetrability. Int J Rock Mech Min Sci 46:1329-1340

Hush DR (1989) Classification with neural networks: a performance analysis. In: Proceedings of the IEEE International Conference on Systems Engineering. Dayton, OH, USA, pp 277-280

ISRM (1978) Suggested methods for determining tensile strength of rock materials. Int. J. Rock Mech. Min. Sci. Geomech. Abstr 15:101-103

ISRM (1979) Suggested methods for determining the uniaxial compressive strength and deformability of rock materials. Int J Rock Mech Min Sci Geomech Abstr 16:135-140

Jaeger JC (1967) Failure of rocks under tensile strength. Int J Rock Mech Min Sci 4: 219-227

Jahed Armaghan D, Tonnizam Mohamad E, Hajihassani M, Alavi Nezhad Khalil Abad SV, Marto A, Moghaddam MR (2015b) Evaluation and prediction of flyrock resulting from blasting operations using empirical and computational methods. Eng Comput doi:10.1007/s00366-015-0402-5

Jahed Armaghani D, Hajihassani M, Sohaei H, Mohamad ET, Marto A, Motaghedi H, Moghaddam MR (2015c) Neuro-fuzzy technique to predict air-overpressure induced by blasting. Arab J Geosci 114

Jahed Armaghani D, Momeni E, Alavi Nezhad Khalil Abad SV, Khandelwal M (2015a) Feasibility of ANFIS model for prediction of ground vibrations resulting from quarry blasting. Environ Earth Sci. DOI 10.1007/s12665-015-4305-y

Kaastra I, Boyd M (1996) Designing a neural network for forecasting financial and economic time series. Neurocomputing 10:215-36

Kahraman S (1999) Rotary and percussive drilling prediction using regression analysis. Int J Rock Mech Min Sci 36: 981-989 
Kahraman S, Balcı C, Yazıcı S, Bilgin N (2000) Prediction of the penetration rate of rotary blast hole drills using a new drillability index. Int J Rock Mech Min Sci 37:729-743

Kahraman S, Bilgin N, Feridunoglu C (2003) Dominant rock properties affecting the penetration rate of percussive drills. Int J Rock Mech Min Sci 40:711-723

Kanellopoulas I, Wilkinson GG (1997) Strategies and best practice for neural network image classification. Int J Remote Sens 18:711-725

Karpuz C, Pasamehmetoglu AG, Dincer T, Muftuoglu Y (1990) Drillability studies on the rotary blast hole drilling of lignite overburden series. Int. J Surf Min Recl 4:89-93

Khandelwal M (2013) Correlating P-wave velocity with the physico-mechanical properties of different rocks. Pure and Applied Geophysics 170(4):507-514

Khandelwal M, Monjezi M (2013) Prediction of backbreak in open-pit blasting operations using the machine learning method. Rock Mech Rock Eng 46(2):389-396

Khandelwal M, Ranjith P G (2010) Correlating index properties of rocks with P-wave measurements. Journal of Applied Geophysics 71(1):1-5

Lee Y, Oh SH, Kim MW (1991) The effect of initial weights on premature saturation in back-propagation learning, In: Proceedings of the International Joint Conference on Neural Networks 765-770

Macias FJ, Jakobsen PD, Seo Y, Bruland A (2014) Influence of rock mass fracturing on the net penetration rates of hard rock TBMs. Tunnel Undergr Sp Technol 44:108-120

Majdi A, Beiki M (2010) Evolving neural network using a genetic algorithm for predicting the deformation modulus of rock masses, Int J Rock. Mech. Min Sci 47:246-253

Masters T (1994) Practical neural network recipes in C++. Boston MA: Academic Press

Matern N von, Hjelmer A (1943) Försök med pågrus (“'Tests with Chippings’’), Medelande nr. 65, Statens väginstitut, Stockholm, 65 pp. (English summary, pp. 56-60). 
Moein MJA, Shaabani E, Rezaeian M (2014) Experimental evaluation of hardness models by drillability tests for carbonate rocks. J Petroleum Sci Eng 113:104-108

Momeni E, Nazir R, Jahed Armaghani D, Maizir H (2014) Prediction of pile bearing capacity using a hybrid genetic algorithm-based ANN. Measurement 57:122-131

Monjezi M, Khoshalan HA, Varjani AY (2012). Prediction of flyrock and backbreak in open pit blasting operation: a neuro-genetic approach. Arab J Geosci 5(3):441-448

Nelson M, Illingworth WT (1990) A Practical Guide to Neural Nets. Addison- Wesley, Reading MA

Paola JD (1994) Neural network classification of multispectral imagery. MSc thesis, The University of Arizona, USA

Rashidian V, Hassanlourad M (2013) Predicting the shear behavior of cemented and uncemented carbonate sands using a genetic algorithm-based artificial neural network. Geotech. Geol Eng 2:1-18

Ripley BD (1993) Statistical aspects of neural networks. In: Barndoff- Neilsen OE, Jensen JL, Kendall WS, editors. Networks and chaos-statistical and probabilistic aspects. London: Chapman \& Hall, pp 40-123

Saemi M, Ahmadi M, Varjani AY (2007) Design of neural networks using genetic algorithm for the permeability estimation of the reservoir. J Petroleum Sci Eng 59:97-105

Schmidt RL (1972) Drillability Studies - Percussive Drilling in the Field, US Bureau of Mines RI 7684

Selim AA, Bruce WE (1970) Prediction of penetration rate for percussive drilling. USBM. RI; p 7396

Selmer-Olsen R, Lien R (1960) Bergartens borbarhet og sprengbarhet, Teknisk Ukeblad, 34, Oslo, pp 311

Sievers H (1950) Die Bestimmung des Bohrwiderstandes von Gesteinen, Glückauf 86: 37/38, pp 776784. Glückauf G.M.B.H., Essen

Simpson P (1990) Artificial Neural System: Foundation, Paradigms, Applications and Implementations, Pergamon, New York 
531 Sonmez H, Gokceoglu C, Nefeslioglu HA, Kayabasi A (2006) Estimation of rock modulus: for intact 532 rocks with an artificial neural network and for rock masses with a new empirical equation. Int. J. Rock Mech Min Sci 43:224-235

534 SPSS Inc. (2007). SPSS for Windows (Version 16.0). Chicago: SPSS Inc

535 Swingler K (1996) Applying Neural Networks: A Practical Guide. Academic Press, New York

536 Tripathy A, Singh TN, Kundu J (2015) Prediction of abrasiveness index of some Indian rocks using soft computing methods. Measurement 68: 302-309

538 539

540 541

542 543

544 545

546 547 548 549 550 551

Wang C (1994) A theory of generalization in learning machines with neural application. PhD thesis, The University of Pennsylvania, USA

Wijk G (1989) The stamp test for rock drillability classification. Int J Rock Mech Min Sci Geomech Abstracts 26:37-44

Yagiz S, Gokceoglu C, Sezer E, Iplikci S (2009) Application of two non-linear prediction tools to the estimation of tunnel boring machine performance. Eng Appl Artif Intel 22(4): 808-814

Yang Y, Zang O (1997) A hierarchical analysis for rock engineering using artificial neural networks. Rock Mech Rock Eng 30:207-222

Yarali O, Kahraman S (2011) The drillability assessment of rocks using the different brittleness values. Tunnel Undergr Sp Technol 26:406-414

Yarali O, Soyer E (2013) Assessment of relationships between drilling rate index and mechanical properties of rocks. Tunnel Undergr Sp Technol 33:46-53

Zorlu K, Gokceoglu C, Ocakoglu F, Nefeslioglu HA, Acikalin S (2008) Prediction of uniaxial compressive strength of sandstones using petrography-based models. Eng Geol 96(3):141-158 